\title{
Enablers and constraints for data use in planning for mobility
}

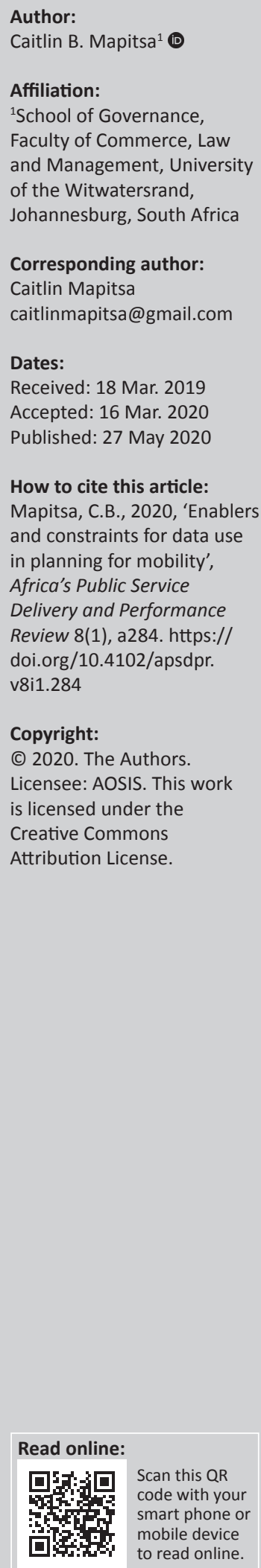

Aim: This article seeks to understand the enablers and constraints to the effective use of data for planning in South African municipalities, by looking at an understudied empirical nexus between migration and the managerial systems of planning.

Settings: Planning is an increasingly critical municipal function, with mobility and shifting settlement patterns reshaping South African municipalities. At the same time, local governance in South Africa is facing multiple crises. In 2019, only 18 out of 257 municipalities received a clean audit, and in 2018, there were more than 250 service delivery protests, a figure that has been increasing steadily for a decade.

Methods: An iterative process of case study development through institutional ethnography took place in six South African municipalities, ranging from rural municipalities to megacities, but focusing on secondary cities and peri urban areas.

Results: The need for stronger management systems at a municipal level in South Africa is well understood. The strengthening of public sector monitoring and evaluation systems is one tool for public sector reforms the government is implementing at all levels of government. However, its effectiveness is threatened by varied incentives to generate and use data to inform decision making.

Conclusion: In doing so, it underscores the ways in which data systems are developed in socially embedded ways, and identifies some data-specific areas that could support municipal management systems to better respond to migration.

Keywords: African cities; decentralisation; evaluation; evidence use; migration; planning.

\section{Introduction}

Rapid urbanisation and the transformation of urban landscapes are the result of the residents of African cities moving. It is increasingly common for people to live both mobile and multi-local lives. However, this is not reflected in the way the local government's planning, monitoring and evaluation systems are being designed. Municipalities are at the coalface of this mobility, with their service delivery mandate, and given the widespread decentralisation that has swept the continent's public sector over the last two decades, municipalities are widely responsible for independent decision-making on a large array of service delivery and management issues (Smith 2017). However, many municipalities have been unable to engage with robust, forward-looking demographic data, or even assumptions of mobility, to allow for proactive planning for the shifting populations (Landau 2018).

Municipal officials in South Africa share not only an assumption that populations are fixed but also carry a normative judgement that sedentary populations are desirable (Blaser \& Landau 2014). As a result of this, the targets and indicators that are being set for municipal performance by largely autonomous administrations do not reflect the reality of a migrating populace and may not be enabling development of the actual population they are governing. Planning systems are largely centralised with upward accountability, not at all multi-local, and therefore do not accommodate the varying needs and developmental diversity of different municipalities.

Similarly, monitoring and data systems are often decentralised, and they hold similar assumptions about the nature of the community. Because of the explicit effort to introduce downward accountability into municipal governance, through the election of local ward counsellors, the independence of municipalities and so on, most service delivery systems in South Africa are geographically bounded (Cameron 2014). In addition, because of efforts to decentralise service delivery, most data collection systems are developed within each service independently (Harrison \& Todes 2015). As a result, 
coordinating information across geographic areas, or across integrated services, is a challenge.

When these two issues are brought together, emerging evaluation systems are caught in a conundrum. Planning systems are centralised, with data collection for monitoring systems decentralised. Both of these systems are designed and analysed by officials who make assumptions that a populace has not and will not move. However, this also offers an opportunity for municipalities to introduce mobility into their analysis, and to lead towards more multi-local planning and data systems. If this could be introduced into the current processes for setting indicators and measuring progress, municipalities might become more responsive to the needs of residents. This article explains the ways in which municipal data respond to the needs of mobile communities, and presents data from both municipal officials and communities that are using mobility as a livelihood strategy. It explains the various constraints to migration-responsive planning, and finally recommends opportunities municipalities have at their disposal to use the available systems and data to better meet the needs of residents whose livelihoods extend beyond their geographic borders.

\section{The migration and data nexus}

This article will engage in two bodies of literature: the first is research understanding the way mobility is generating new forms of state practice; the second is the literature in public administration that is looking at the spatialisation of planning and the decentralisation of municipal monitoring and evaluation systems. It will focus on work that highlights the importance of mobility for municipal planning, and in analysis, will address issues of how planning is currently spatialised, and what multi-local planning could look like. It will particularly consider this in line with emerging discussions about the evolution of South Africa's national evaluation system, which is shaping the way the public sector is engaging with monitoring and evaluation data for planning.

\section{Mobility and state practice}

The way mobility is shaping state practice has been gaining attention in recent years. As the book Mobility Makes States argues (eds. Vigneswaran \& Quirk 2015), the way people move across boundaries is as fundamental to understanding a state as the boundaries themselves. This is what Faist (2013) called the 'mobility turn', as more of a social paradigm or diagnostic lens for assumptions about the world, rather than an isolated field of study. As he asks, 'What is this new norm normalising?'

The field of migration has often been like a pendulum, swinging between framing migration as a problem for development, and a solution (Jordon 2020; Schiller \& Faist 2014). This narrative has often been framed by Northern governments and international organisations, which has created an asymmetry in the discussion around who counts as a migrant, and what the social and economic causes and consequences of migration are. Increasingly, scholars of urban studies and those of migration are engaging with similar theoretical frameworks for understanding the complex interconnected relationships between geography, mobility and power.

Most research looking at the way states shape migration have focussed on large-scale, international migration and the nation state. From the slave trade to regional labour migration, there is a large body of scholarship on states driving various forms of mobility (Brubaker 2010; Levitt \& De La Hasa 2003; Wimmer \& Glick Schiller 2002). However, while this research takes these trends into account, it focusses equally at the municipal level considering the role of the state in influencing 'micro-mobility'. Through municipal planning and service delivery decisions, local government authorities are determining how plots are zoned, where infrastructure is provided and where upgrading takes places. South Africa's Spatial Planning Land Use Management Act (SPLUMA) has given widespread powers to municipal governments to make land-use determinations. These drive settlement patterns of migrants within municipalities (eds. Bauböck \& Faist 2010), and the way this fits into the local community migration dynamics, is important for understanding both local government practice and mobility (Blaser Mapitsa 2019).

Similarly, migrants are also imagining public authorities in their places of origin and residence, and these expectations are shaping the ways migrants interact with authorities (Crush \& Ramachandran 2017). For example, experiences of police violence are not only shaping migrant decision-making in the migration process itself, but they are also shaping localities of residence, willingness to report crimes and involvement in community forums (Bowling \& Sheptycki 2017).

\section{Indicator development and place}

Moving from looking at the social components of managing a migratory municipality, it is equally important to understand the actual mechanisms of management within municipal structures. Municipalities are driven by planning processes that involve targets and indicators to remain compliant to legislation and effectively deliver services (Selepe 2018). African governments are currently undergoing a wave of developing national monitoring and evaluation systems, and are aligning data emerging from departments and national statistical agencies with long-term development plans (Phillips et al. 2014).

The Department of Planning, Monitoring, and Evaluation (DPME) has been building a national evaluation system in South Africa since 2011. The department was established in 2009, largely in response to dissatisfaction of leadership in government about poor performance on service delivery. The initial directive was to focus heavily on monitoring and accountability, but as it grew, the importance of a learning and performance improvement mandate also grew, culminating in the creation of an evaluation function (Goldman et al. 2015). 
At the same time, the government was required to balance the effectiveness of a performance management system with limited capacity, and also to broaden its geographic and institutional focus and scope. With this in mind, the process of localising the national evaluation system has been phased, with Provincial Evaluation Plans being introduced since 2015, and support gradually extending to municipalities that are already demonstrating components of results-based management.

It has become evident in the decentralisation of the evaluation system that for accurate setting of targets and indicators, multi-local planning is essential. However, there are relatively few mechanisms in place to facilitate multi-local planning. This article will explore both the frustrations municipal officials and residents experience when planning is geographically bounded in ways that the lives of residents are not, as well as opportunities for integrating mobility into municipal planning and management systems.

\section{Methods}

This article draws on research from six South African municipalities in the provinces of Gauteng, Limpopo and Mpumalanga. Fieldwork was conducted over a period of 18 months. At each site, multi-methods research was carried out through an iterative process that included community mapping, focus groups, key stakeholder interviews and participant observation. Because of political and security concerns, individual respondents and, as far as possible, specific municipalities are kept anonymous. Interviews are cited through respondent coding that anonymise location and occupation.

Through an inductive process, a diagnostic tool was developed that looks at the competencies municipalities need to respond effectively to migration (Blaser \& Landau 2014). The six dimensions of mobility responsiveness were identified as data collection and use, budgeting, participation, accountability, perceptions and social cohesion. They were included to span a range of technical, institutional and political requirements for a municipality. While they are all important for different reasons, this article will focus particularly on the dimension of data collection and use.

\section{Geographically bounded planning}

This study has found a 'sedentarist' bias across systems of municipal data generation and use, falling broadly into two categories. The first is a bias in planning systems, which has led to the setting of targets and indicators that include assumptions of a sedentary population. An outcome of this has been an incentive to ignore the ways in which mobility could enable development, which can be seen in planning systems. The second is around Monitoring and Evaluation (M\&E) and data management systems, which are both decentralised and geographically grounded. This limits their effectiveness in measuring development outcomes that are spread across municipal boundaries.

\section{Migration and planning systems}

There is rich literature to suggest that individuals migrate as a strategy to boost household income, access better services and diversify risk (Castelli 2018; Bakewell 2008; Silvey, 2004). Public officials, on the contrary, generally hold a negative view of the migration process, with perceptions that it is something problematic, and possibly something to be controlled or minimised (Bauman 2011; Sassen 1999; Schapendonk 2018). While these attitudes permeated the research findings, they do not themselves constitute a new contribution to debates on planning or migration. When brought together with municipal evaluation systems, however, migration has something important to offer. A lens of migration illustrates that municipalities are not necessarily taking citizens' experiences or aspirations into account, as municipal officials set targets for successful development. This can be seen in the chasm between municipal discourse around migration as a problem, and individual experiences framing migration as hope, and multi-locality as a coping strategy (ed. Samaddar 2018).

As an example, Bushbuckridge was one site of study. It is a rural community that has a relatively high dependency ratio and high levels of out migration. At the same time, it is situated near the border of Mozambique and has a long history of migration from Mozambique. The municipality's Integrated Development Plan (IDP) contains a Strengths, Weaknesses, Opportunities, and Threats analysis, and places both immigration and migrant labour as threats, clearly demonstrating that they are not viewed as either strengths or opportunities (Bushbuckridge Municipality 2014).

Were the municipal officials of Bushbuckridge to consider mobility as an opportunity in the way most residents do, they may act towards it quite differently. Many municipal officials spoke about the way that it is currently problematised. For example:

'Look, on migrants.....we don't have a border post like Komantiapoort, so it is not so big for us. But we do have one office of home affairs. If we hear someone is here illegally, we report them. If we find anyone has come to do criminal things, the police do get involved. We have removed the spaza owners from Zimbabwe, so we are doing things to support people.' (Interview R5M 4AM)

Another official speaks about the difficulty mobility causes for local planning:

'When we do the IDPs, we are going to the communities and finding what they need. Usually it is water. So we make a note, that this settlement needs water. But we find that by the time things have been procured, the people who were living there have moved [to the township].' (Interview B2F 8PV)

This contrasts sharply to the way residents and migrants themselves view the process. One local authority acknowledged that:

'The big houses by the tar road, they are built by migrant remittances. There are no jobs here, no local economy. If people want to make money, their best chance is to leave.' (Interview M4M 3UH). 
This was echoed by men and women alike, across the socioeconomic spectrum. One woman pointed out:

'I didn't want to just survive on my child support grant, so I went to Johannesburg.' (Interview P8F 4ML)

Similar sentiments were shared by dozens of members of the community, who viewed migration at worst as a necessary means of survival, and at best, a great opportunity for upward mobility.

The challenge then comes when this disjuncture is translated into the municipal planning process. For example, in the category of Local Economic Development, the primary opportunity seen by a rural municipality is its geographic location near to the Kruger National Park and associated tourism. As a result, the only goal to enhance local economic development is acceleration of land claims by department of land affairs (IDP 2016/17, cited in Bushbuckridge Municipality 2014). While this is certainly important and fundamental to the community, this issue spans far beyond the 5-year timeline of integrated development planning, and little of the authority around land restitution is at the municipal level, already indicating a mismatch between the level of planning and the level of anticipated results. People living within the community are making immediate decisions about their livelihood, where migration is more relevant than longer-term tourism opportunities. If the municipality acknowledged the importance of migration for local economic development in practice, they may invest in different strategies to boost the local economy. They may also be able to better harness or organise the current economy, which focusses heavily on migrant work and remittances, to support coordinated planning.

A related problem of planning around mobility was noted by an official in Hammanskraal, which is a peri-urban area in Gauteng that receives both inward migration from rural areas and informal settlements, but also sends residents to Johannesburg and Pretoria. One official mentioned:

'It's one step forward, two steps back, because we are trying to decrease the number of people who are indigent. But when people earn more, they move out, and the people who are coming are still looking for work. Because of this, we're always failing.' (Interview J2M 8FC)

Another official in the same department highlighted a similar issue:

'When we're trying to see how we're doing, you realize, we don't know who is going, and we don't know who is coming. You might think it's under control, but then you find a new settlement is springing up. Or a case was under control, but suddenly, boom, the child is living elsewhere. How do we know if he is now able to get the grant where he is?' (Interview P6F 4NJ)

This is where the issue of deliberate target setting becomes essential, in a way that sets municipalities up for measuring progress accurately, acknowledging that residents' lives are not fixed within municipal boundaries.
This section has highlighted some of the ways in which municipal officials are looking at migration primarily as a problem, whereas community members are acting on it as an opportunity. These divergent approaches are leading to challenges in the planning processes. It demonstrates that in creating evaluation systems and setting targets for the municipality, there is a divergence in understanding both the roots and the effects of mobility. The result is that there is no consensus about how municipal programmes should most effectively respond. The 'Data management and multilocality' section will discuss how a lens of mobility, taking into account the multi-local lives many residents live, could change the way success is measured.

\section{Data management and multi-locality}

When it comes to data generation, South Africa enjoys stronger systems and structures for data collection than many countries in the region. However, this advantage falters when applied to migration. The national statistical agency itself Statistics South Africa (StatsSA) recognises that available data on migration are:

... [G]enerally scanty, patchy and skewered. Such shortcomings tend to negatively influence policies, debates, dialogues, etc. as well as distort communication about migration. This contributes to anti-migrant sentiments that could lead to harmful stereotyping, discrimination and even xenophobia. (Budlender 2013)

While the limited availability of reliable and quality data is certainly a constraint, it is certainly not the only, and possibly not the most important, limitation to data use by municipal officials for planning. As one member of the research team found in Botswana:

[A]t the most basic level, demographic data is not available or sufficiently nuanced to provide the basis for urban planning. Yet it is not data paucities alone that are at issue. Rather, it is political and institutional structures that work most strongly against forward looking planning. (Campbell 2014)

StatsSA has taken steps to improve the situation, introducing more migration-related data into both the census and the community survey. However, there is currently a vicious cycle between the marginalisation of migration as a central issue to planning, and the availability and accessibility of high-quality and relevant data.

One health practitioner highlighted this as a challenge, linking it to the way target setting is done:

'We are pushed so much to increase adherence to antiretrovirals [ARVs]. It's drummed in. But we know people go to Lesotho in December and can't follow treatment there.' (Interview J6F 4KD)

Another community health worker also mentioned that migration was making it difficult to know the quality of their adherence data. She said:

'[Y]ou find we have many people dropping out, but then, that is not the case. Those people are sticking to treatment, they've just gone elsewhere. So you are going to say things were not working well, but actually they are.' (Interview M2M 7SV) 
Officials from several other sectors cited the challenges in 'losing' people in otherwise effective service delivery programmes, when some sort of transfer process was supposed to take place. Others highlighted the opposite problem. As one social worker pointed out:

'We are supposed to reach all indigent households in the community. So when the number of households we reach increases, we think we are doing well. But in the meantime, we find these are people who are coming into the community. How do we know if our reach is actually improving, or if the numbers in the community are increasing?' (Interview F3M 4CL)

At a departmental level, officials are both aware and frustrated by the way migration is affecting their results while simultaneously not included in their planning. However, there seem to be many obstacles to building systems of more responsive, coordinated planning, which require interrogation.

\section{Migration and evaluating public management}

South Africa's national evaluation system has burgeoned in recent years, with a National Evaluation Policy Framework adopted in 2011, which initially addressed only national departments, but is now being expanded to apply to provinces and municipalities (Eresia-Eke \& Boadu 2019). This is encouraging municipalities to think critically in assessing the monitoring data at their disposal, and to evaluate the effectiveness of various service delivery interventions. While building performance-based systems within the public sector is laudable, the more these are decentralised, the more important it becomes to consider multi-locality in evaluating a municipality's progress (Coulibaly \& Lima 2018).

Increasingly, evaluation systems are being established to shape the way targets are set and analysed (Fourie 2018). This is an opportunity to bring an awareness of mobility into the way municipalities and provinces are measuring the success of their programmes. However, it has already been acknowledged in the planning domain that this shift is not easy, and geographically rooted governance is the norm. Scholars from urban management have found that (Allen 2003:146):

Geographical and administrative boundaries prevent a strategic approach to environmental planning and management of the peri-urban interface that is holistic enough to include concerns at the city/region level and simultaneously take into consideration the specific problems affecting peri-urban dwellers. Neither the immediate priorities of periurban communities nor the longerterm issues affecting the sustainability of the city/region are likely to be addressed by municipal authorities unless specific fora are set up for this purpose.

At the same time, one of the challenges for building evaluation systems at provincial and municipal levels is the already existing multiplicity of fora without the requisite resources to support and sustain their operations. As one official summed it up:

'Sometimes, we coordinate at the expense of service delivery.' (Interview G2H 4AX)
At the same time, Allen highlighted the need for this coordination to have more effective service delivery, particularly in connection to peri-urban areas. He highlighted that (Allen 2003:138):

[T]his interface demands a conceptual and methodological shift from the physical definition of urban and rural areas (understood as clearly limited geographic and administrative entities) to a broader understanding, whereby the complex patterns of settlement and resource use, the flow of natural resources, of capital, goods, services and people, do not fit or accord with jurisdictional boundaries.

This is precisely what scholars of migration are underscoring. Responding effectively to migrants does not just require considering an additional locality or community, it requires a conceptual shift (Laundau 2018).

While there are cases of individual officials who have made the conceptual shift, aligning entire public-sector institutions to be responsible to mobility requires shifting institutional incentive structures. Currently, municipal management environments are overwhelmingly compliance focussed (Ntshakala \& Nzimakwe 2017). This is in part because compliance with the auditor general implies a significant reporting load, without which municipalities face logistical, financial and administrative consequences (Selepe 2018). However, the national evaluation system with its performance focus does not have the same legislative force behind it. If municipalities must prioritise on the basis of limited human and financial resources, innovations, even if they may lead to improved service delivery, may seem like a luxury.

Perhaps, one of the biggest challenges to introducing multilocality in evaluating government performance is that it may make explicit trade-offs that are politically unpopular, or contestations that are difficult to confront with a technical approach. This is already a challenge in planning, and when players from different geographical jurisdictions are included, it could add an additional dimension to the contestation. It would require officials to confront development dilemmas, such as whether one locality can increase its economic development at the expense of another, or whether investing in employment generation in one place leads to higher dependency ratios in other places. While this may be a political problem for those who govern municipalities, it is precisely through engaging with these trade-offs that people choose to lead multi-local lives. One migrant articulated this calculation by saying:

'I don't like being away from my children, but I need to come where there is work, and they have a better school with my mother.' (Interview G4F 9RQ)

At the moment, public-sector target setting is largely migration blind. At best, it encapsulates some of the ways through which migration is a problem and may target ways in which illegal or informal migration is limited or controlled. At worst, it may disincentivise recognising some of the ways in which migration can support development. Most likely, it is somewhere in the 
middle, not effectively supporting some of the positive contributions migration could make to development but also doing very little to set targets meaningfully across a range of changing demographic factors.

\section{Conclusion}

It is not easy for emergent evaluation systems at a municipal level to be responsive to mobile populations. There are a range of challenges for effectively integrating migration in municipal planning systems. These include being embedded in centralised planning systems as well as decentralised monitoring systems that both assume people do not move. This article has demonstrated the limitations this creates for both appropriateness and rigour of an evaluation system that should respond to the needs of a populace. However, it also creates an opportunity to introduce multi-local considerations into the existing system.

Municipal authorities share an acknowledgement that mobility is shaping the communities they govern in important and fundamental ways. However, officials are not equipped with the systems, data, mandate or understanding to plan an effective response to migration. In a few emergent cases, grappling with these collective constraints on effective planning may be leading to new forms of collaboration. Creating platforms to support this collaboration could be a first step in building municipal capacity to be more responsive to mobility. Building on municipal practice in places where there is already awareness and political will increases the chances of success.

As cities emerge as important centres of power in an agenda of global transformation, there is an urgency in looking at the possibilities and limits local government faces in effective planning, and what new forms of management systems may be required to facilitate the implementation of these plans. Steps taken by South African metros to integrate themselves into the national evaluation systems hold promise in this regard and can help individual officials overcome institutional constraints to responsive planning.

\section{Acknowledgements}

The authors thank Kutala Pungwa for her invaluable insights and support in drafting this manuscript.

\section{Competing interests}

The author has declared that no competing interests exist.

\section{Author's contributions}

I declare that I am the sole author of this research article.

\section{Ethical consideration}

Ethical clearance was obtained for the wider research project of which this manuscript forms a part.

\section{Funding information}

This research received no specific grant from any funding agency in the public, commercial or not-for-profit sectors.

\section{Data availability statement}

Data sharing is not applicable to this article as no new data were created or analysed in this study.

\section{Disclaimer}

The views and opinions expressed in this article are those of the authors and do not necessarily reflect the official policy or position of any affiliated agency of the authors.

\section{References}

Allen, A., 2003, Environmental planning and management of the peri-urban interface: Perspectives on an emerging field, Environment and Urbanization 15(1), 135-148.

Bakewell, O., 2008, “Keeping them in their place": The ambivalent relationship between development and migration in Africa', Third World Quarterly 29(7) 1341-1358. https://doi.org/10.1080/01436590802386492

Bakewell, O. \& Landau, L.B. (eds.), 2017, Forging African communities: Mobility, integration and belonging, Springer, New York, NY.

Bauböck, R. \& Faist, T. (eds.), 2010, Diaspora and transnationalism: Concepts, theories and methods, Amsterdam University Press, Amsterdam.

Bauman, Z., 2011, 'Migration and identities in the globalized world', Philosophy \& Social Criticism 37(4), 425-435. https://doi.org/10.1177/0191453710396809

Blaser, C. \& Landau, L.B., 2014, Managing migration in Southern Africa: Tools for evaluating local government responsiveness, University of Sussex, Sussex.

Blaser Mapitsa, C., 2019, 'Migration governance as place making: South African experiences', Journal of Place Management and Development 12(3), 391-407. https://doi.org/10.1108/JPMD-11-2017-0116

Bowling, B. \& Sheptycki, J., 2017, 'Global policing, mobility and social control', in S. Pickering \& J. Ham (eds.), The Routledge handbook on crime and international migration, pp. 87-104, Routledge, Oxfordshire.

Brubaker, R., 2010, 'Migration, membership, and the modern nation-state: Internal and external dimensions of the politics of belonging', The Journal of Interdisciplinary History 41(1), 61-78. https://doi.org/10.1162/jinh.2010.41.1.61

Budlender, D., 2013, Improving the quality of available statistics on Foreign labour in South Africa: Existing data sets, MiWORC Report, 2, African Centre for Migration \& Society, Johannesburg.

Bushbuckridge Municipality, 2014, Integrated development plan 2014-2016, Bushbuckridge Local Municipality, Bushbuckridge.

Campbell, E., 2014, 'Migration and City Governance in Botswana: The Case of Gaborone', Unpublished Research Report, African Centre for Migration \& Society, Johannesburg.

Cameron, R., 2014, 'Vertical decentralisation and urban service delivery in South Africa: Does politics matter?', Development Policy Review 32(Suppl 1), S81-S100. https://doi.org/10.1111/dpr.12070

Castelli, F., 2018, 'Drivers of migration: Why do people move?', Journal of Travel Medicine 25(1), tay040. https://doi.org/10.1093/jtm/tay040

Coulibaly, H. \& Lima, S., 2018, 'Decentralisation and territorialisation of migratory resources in Mali: Towards which local and transnational governance?', in T. Lacroix \& A. Desille (eds.), International migrations and local governance, pp. 97-110, Palgrave Macmillan, Cham.

Crush, J. \& Ramachandran, S., 2017, Migrant entrepreneurship collective violence and Xenophobia in South Africa, Southern African Migration Programme, Waterloo.

Eresia-Eke, C.E. \& Boadu, E.S., 2019, 'Monitoring and evaluation preparedness of public sector institutions in South Africa', Journal of Reviews on Global Economics 8, 532-542. https://doi.org/10.6000/1929-7092.2019.08.46

Faist, T., 2013, 'The mobility turn: A new paradigm for the social sciences?', Ethnic and Racial Studies 36(11), 1637-1646. https://doi.org/10.1080/01419870.2013.812229

Fourie, W., 2018, 'Aligning South Africa's National Development Plan with the 2030 Agenda's Sustainable Development Goals: Guidelines from the policy coherence for development movement', Sustainable Development 26(6), 765-771. https:// doi.org/10.1002/sd.1745

Goldman, I., Mathe, J.E., Jacob, C., Hercules, A., Amisi, M., Buthelezi, T. et al., 2015 'Developing South Africa's national evaluation policy and system: First lessons learned', African Evaluation Journal 3(1), 1-9. https://doi.org/10.4102/aej.v3i1.107

Harrison, P. \& Todes, A., 2015, 'Spatial transformations in a "loosening state": South Africa in a comparative perspective', Geoforum 61, 148-162. https://doi org/10.1016/j.geoforum.2015.03.003

Jordan, B., 2020, 'Mobility and migration', in B. Jordan (ed.), Authoritarianism and how to counter it, pp. 51-62, Palgrave Pivot, Cham. 
Landau, L.B., 2018, 'Conclusion: Archipelagos and estuaries: Mobility, local authorities and the governance of multiple elsewheres', in T. Lacroix \& A. Desille (eds.) International migrations and local governance, pp. 215-231, Palgrave Macmillan, Internation
Cham.

Levitt, P. \& De La Dehesa, R., 2017, 'Rethinking "transnational migration and the redefinition of the state" or what to do about (semi-) permanent impermanence', definition of the state" or what to do about (semi-) permanent impermanence',
Ethnic and Racial Studies 40(9), 1520-1526. https://doi.org/10.1080/01419870.2 Ethnic and Racia

Ntshakala, T. \& Nzimakwe, T.I., 2017, 'Performance auditing as a mechanism for effective service delivery in South African local government', Journal of Public Administration and Development Alternatives (JPADA) 2(1), 67-81.

Phillips, S., Goldman, I., Gasa, N., Akhalwaya, I. \& Leon, B., 2014, 'A focus on M\&E of results: An example from the Presidency, South Africa', Journal of Development Effectiveness 6(4), 392-406. https://doi.org/10.1080/19439342.2014.966453

Samaddar, R. (ed.), 2018, Migrants and the Neoliberal City, Orient BlackSwan, Hyderabad.

Sassen, S., 1999, Globalization and its discontents: Essays on the new mobility of people and money, New Press, New York, NY.
Schapendonk, J., 2018, 'Navigating the migration industry: Migrants moving through an African-European web of facilitation/control', Journal of Ethnic and Migration an African-European web of facilitation/control', Journal of Ethnic and Migra
Studies 44(4), 663-679. https://doi.org/10.1080/1369183X.2017.1315522

Schiller, N.G. \& Faist, T. (eds.), 2010, Migration, development, and transnationalization: A critical stance, vol. 12, Berghahn Books, Oxford.

Selepe, M.M., 2018, 'The assessment and enhancement of performance management within the South African Local Government environment', International Conference on Public Administration and Development Alternatives, Saldanhabay.

Silvey, R., 2004, 'Power, difference and mobility: Feminist advances in migration studies', Progress in Human Geography 28(4), 490-506. https://doi org/10.1191/0309132504ph490oa

Smith, M.P., 2017, 'Transnational ties: Cities, migrations, and identities', in J. Eade (ed.), Transnational ties, pp. 3-13, Routledge, New York, NY

Vigneswaran, D. \& Quirk, J. (eds.), 2015, Mobility makes states: Migration and power in Africa, University of Pennsylvania Press, Philadelphia, PA.

Wimmer, A. \& Glick Schiller, N., 2002, 'Methodological nationalism and beyond: Nation-state building migration and the social sciences', Global Networks 2(4), 301-334. https://doi.org/10.1111/1471-0374.00043 